\title{
ASPECTOS SOCIAIS NA ESCOLHA PELA LICENCIATURA EM FÍSICA: UMA ANÁLISE EM UNIVERSIDADES DO RIO GRANDE DO SUL'
}

\author{
LUISA MARIANA DA SILVA "* \\ https://orcid.org/0000-0001-7884-2425 \\ RAFAEL DE CARVALHO BARBOSA 11 ** \\ https://orcid.org/0000-0002-5343-9477
}

RESUMO: Este trabalho discute alguns aspectos sociais associados à escolha pela Licenciatura em Física em duas instituições de Ensino Superior: a Universidade Federal de Santa Maria (UFSM) e a Universidade Federal do Rio Grande do Sul (UFRGS). Primeiramente são apresentados os resultados referentes à origem escolar dos concorrentes. Observou-se que a maior parte dos alunos realizou o Ensino Médio em escolas públicas. Posteriormente, foi analisada a origem familiar desses candidatos. Em relação à escolaridade, a maior parte é oriunda de famílias em que os pais possuem, em geral, o Ensino Médio completo. Em relação à origem econômica, é possível dizer que esses candidatos são oriundos de classes menos favorecidas. Nossos resultados sugerem um certo padrão no perfil dos que buscam o curso de Licenciatura em Física nas instituições estudadas.

Palavras-chave: Sociologia da Educação; Pierre Bourdieu; Ensino de Física.

\section{SOCIAL ASPECTS ABOUT THE CHOICE OF THE LICENTIATE DEGREE IN PHYSICS: AN ANALYSIS IN UNIVERSITIES OF RIO GRANDE DO SUL}

ABSTRACT: This paper discusses some social aspects associated to the choice of the Licentiate in physics in two higher education institutions: UFSM and UFRGS. First, the results concerning the places where the competitors studied before are presented. It is observed that most of the students studied in public schools during high school. After, the origin of the families of these candidates was
"Estudante do Curso Técnico em Informática integrado ao Ensino médio do Instituto Federal de Educação, Ciência e Tecnologia do Rio Grande do Sul/Campus Rolante. Participante do Grupo de Pesquisa Ensino e Aprendizagem de Física do IFRS/CNPq.

E-mail: < luu.marianaa@gmail.com>

"Instituto Federal de Educação, Ciência e Tecnologia do Rio Grande do Sul/Campus Bento Gonçalves. Professor da Educação Básica, Técnica e Tecnológica. Doutor em Ciências: Área de Concentração Física Teórica/Universidade Federal do Rio Grande do Sul. Participante do Grupo de Pesquisa Ensino e Aprendizagem de Física do IFRS/CNPq.

E-mail:<rafael.barbosa@bento.ifrs.edu.br >.

\footnotetext{
I Trabalho realizado com apoio do Conselho Nacional de Desenvolvimento Científico e Tecnológico(CNPq).

" Instituto Federal de Educação, Ciência e Tecnologia do Rio Grande do Sul, Campus Rolante, RS, Brasil.

III Instituto Federal de Educação, Ciência e Tecnologia do Rio Grande do Sul, Campus Bento Gonçalves, RS, Brasil..
} 
analyzed. In relation to schooling, most of these candidates are from families that parents have, in general, high school degree. Regarding to economic issues, it can be said that these candidates come from less favoured social classes. Our results suggest a certain pattern in the profile of candidates who are pursuing the Licentiate degree in Physics in the institutions that we analyzed.

Keywords: Sociology of Education; Pierre Bourdieu; Physics Teaching.

\section{ASPECTOS SOCIALES EN LA ELECCIÓN DE LA LICENCIATURA EN FÍSICA: UN ANÁLISIS EN UNIVERSIDADES DE RIO GRANDE DO SUL}

RESUMEN: Este trabajo discute algunos aspectos sociales relacionados con la elección de la Licenciatura en Física en dos instituciones de Enseñanza Superior: la Universidad Federal de Santa Maria (UFSM) y la Universidad Federal de Rio Grande do Sul (UFRGS). Primeramente se presentan los resultados referentes al origen escolar de los competidores. Se observó que la mayor parte de los alumnos realizaron la Enseñanza Media en colegios públicos. Posteriormente se analizó el origen familiar de esos candidatos. En relación con la escolaridad, la mayor parte proviene de familias en que los padres concluyeron, en general, la Enseñanza Media. Con respecto al origen económico, es posible decir que esos candidatos provienen de clases menos privilegiadas. Nuestros resultados sugieren un cierto patrón en el perfil de los que buscan la carrera de Licenciatura en Física en las instituciones estudiadas.

Palabras clave: Sociología de la Educación; Pierre Bourdieu; Enseñanza de Física. 


\section{INTRODUÇÃO}

Os desafios cotidianos encontrados por professores e alunos da educação brasileira são persistentes e bastante significativos. As dificuldades apresentam-se das mais diversas formas, desde o baixo investimento praticado pelo governo, até a progressiva desvalorização que a educação vem enfrentando nos últimos tempos (LÜDKE, 2004).

Apesar do aumento do número de alunos ingressantes no Ensino Superior, uma quantidade menor de alunos oriundos do Ensino Médio tem procurado os cursos de licenciatura plena. De acordo com dados comparativos do Censo de Educação Superior de 2013, a busca por cursos de licenciatura é menor, mesmo quando comparada aos cursos de bacharelado das respectivas disciplinas (INEP/ MEC, 2013). A profissão docente vem sofrendo, no decorrer dos anos, um contínuo processo de desvalorização (LÜDKE, 2004), e a visão da sociedade em relação à profissão não é vista com tanto prestígio (CERDEIRA, 2010).

Nesse sentido, a diminuição do número de professores das áreas das ciências da natureza na educação básica tem sido, em especial, motivo de atenção do poder público. Uma das alternativas adotadas por órgãos responsáveis pela educação brasileira, como o Ministério da Educação (MEC), foi de expandir o número de cursos de formação de professores pelo país, sejam na modalidade à distância, como é o caso da Universidade Aberta do Brasil (UAB), sejam na modalidade presencial, através das Universidades públicas e dos Institutos Federais de Educação Básica, Técnica e Tecnológica. Durante o período de 2009 até 2013, é possível observar um aumento de mais de 10\% no número de cursos de licenciatura em todo o Brasil, entre instituições públicas e privadas, conforme o Censo da Educação Superior (INEP/MEC, 2013). Apesar desse incremento no número de cursos que oferecem a formação profissional de professor e uma quantidade maior de licenciados formados no Brasil, a carência no número de professores da disciplina de Física é notável (IBAÑEZ RUIZ, 2007).

Uma quantidade significativa de pesquisas tem procurado entender o porquê desse movimento, principalmente em relação aos cursos de licenciatura das áreas das Ciências da Natureza (DINIZ-PEREIRA, 2015; IBAÑEZ RUIZ, 2007; LUNKES, 2011; OLIVEIRA, 2013; RODRIGUES, 2009; SANTOS, 2013; SÁ, 2011). Porém, a maioria desses trabalhos não foca sua atenção nas características sociais dos jovens que estão nas escolas e que estão procurando ingressar em cursos superiores dessas áreas. Por exemplo, quais são suas origens econômicas e familiares e de que maneira isso está relacionado ao processo de escolha pelo curso de Licenciatura em Física? É nesse contexto em que se insere o presente estudo. Nele, visamos compreender o perfil do candidato que busca o ingresso no curso de Licenciatura em Física em instituições de Ensino Superior específicas. Para tanto, selecionamos duas diferentes universidades no estado do Rio Grande do Sul: uma na capital (Universidade Federal do Rio Grande do Sul - UFRGS) e outra no interior do estado (Universidade Federal de Santa Maria - UFSM).

Portanto, temos como objetivo analisar se a opção por uma profissão está associada a um perfil socioeconômico comum entre os concorrentes desses concursos vestibulares. A questão é: o quanto a origem socioeconômica interfere na escolha do 
curso superior/profissão? Há uma clara relação entre esses aspectos? Desse modo, iremos focar nossa atenção, principalmente, nos processos seletivos para o curso de Física - Licenciatura Plena - Diurno das universidades federais mencionadas.

\section{HABITUSE OS GOSTOS DE CLASSE}

De acordo com Bourdieu (2007), os diferentes espaços socialmente ocupados estão relacionados aos estilos de vida desenvolvidos. Isso quer dizer que os espaços ocupados dentro de uma estrutura social e as relações que cada indivíduo estabelece estão relacionados ao estilo de vida desempenhado por certo agente social. A prática desse agente social é determinada a partir do que é denominado por Bourdieu como habitus. O babitus pode ser compreendido como um conjunto de disposições incorporadas conforme o meio social do qual os indivíduos fazem parte. O habitus é a estrutura que organiza as práticas e a percepção das práticas (BOURDIEU, 2001), ou seja, funciona como o princípio gerador e estruturador das práticas e das representações.

É nesse sentido que o conceito de habitus possui um papel central na teoria de Pierre Bourdieu (1992). Esse conceito encontra-se em uma região intermediária entre o subjetivismo e o objetivismo do mundo social. Bourdieu argumenta que a estrutura das práticas sociais não é um processo que ocorre de maneira mecânica do exterior para o indivíduo de acordo com as condições objetivas que estão naquele espaço. A proposta do autor também vai de encontro com o pensamento subjetivista, no qual existe uma grande valorização do indivíduo, em que todas as suas ações ocorreriam de maneira autônoma e consciente. Assim, as práticas sociais são estruturadas ou, ainda, definidas conforme o espaço social que um determinado indivíduo ocupa. Essas práticas possuem características típicas das pessoas que pertencem a esse meio. Por isso, a maneira com que as pessoas percebem o mundo, seus gostos e predileções estão relacionadas com o meio ao qual essas pessoas pertencem. Isso quer dizer que as ações individuais não são completamente livres da estruturação, mas também não significa que os indivíduos não possuam quaisquer formas de autonomia ou ingerência sobre suas decisões (ORTIZ, 1983).

Uma vez que o habitus está relacionado àquilo que foi estruturado externamente e que, por consequência, estrutura as práticas individuais dos agentes, então o habitus está associado àquilo que gera o gosto de classe. Assim, o gosto pode ser associado aos princípios que estão vinculados ao estilo de vida. Para Pierre Bourdieu, a maneira que as pessoas observam o mundo está relacionada com a posição social que ele ocupa e com a forma que essa posição social relaciona-se com os bens culturais disponíveis. Existem aqueles que compreendem que uma obra de arte está inserida em um campo artístico, e a maneira legítima de compreender aquela obra é a partir de sua forma. Já as camadas sociais com menor capital cultural compreendem uma obra de arte a partir de sua função. A composição de uma obra em um determinado espaço, ou em expressões faciais cotidianas ou associações com situações mais próximas a essas pessoas podem ter diferentes significados, dependendo da posição social do indivíduo (BOURDIEU, 2007).

É nesse contexto que Pierre Bourdieu propõe o conceito de capital cultural, expressão proposta para compreender os diferentes destinos escolares de acordo 
com seus grupos sociais de origem. O capital cultural pode ser diferenciado a partir de três diferentes formas: o incorporado, o objetivado e o institucionalizado. $\mathrm{O}$ incorporado seria a forma que exige a inserção e acumulação e, com isso, demanda certo investimento do próprio sujeito. Assim, aquele que possui essa forma de capital cultural investiu tempo para essa incorporação. O capital cultural incorporado não possui sua transferência instantânea, ou seja, muitas vezes permanece com o portador desse capital, não sendo transmitido ao longo do tempo às pessoas que habitam seu meio social. Essa forma de capital demanda um considerável investimento de tempo para se tornar parte do conjunto de disposições duráveis.

Por sua vez, o capital cultural objetivado é transferível. Existe na forma de bens como obras de artes e materiais literários, por exemplo. Para a aquisição desse tipo de material, é necessária a aplicação de recursos econômicos, ou como define Pierre Bourdieu, capital econômico. Porém, para a aquisição desses materiais é preciso possuir o capital cultural na forma incorporada para apropriarse simbolicamente desses objetos. Por fim, o capital cultural institucionalizado também pode ser associado ao capital cultural incorporado, sendo que essa forma de capital está representada por meio da aquisição de títulos que são reconhecidos e garantidos institucionalmente. Essa forma de capital cultural está relacionada ao investimento na carreira acadêmica e escolar, porém esse investimento pode estar associado a questões pragmáticas, ou seja, o quanto o sujeito investe e o possível retorno que esse investimento pode conceder a ele (BOURDIEU, 1997).

Portanto, o habitus é considerado como um princípio gerador de práticas objetivamente classificáveis e, além disso, consiste em um sistema de classificação dessas práticas. Assim, o habitus produz práticas e também a capacidade de apreciar essas práticas. O babitus produz, por exemplo, uma obra de arte e também a capacidade de apreciar essa obras (BOURDIEU, 2007).

Ainda de acordo com o mesmo autor (2007), cada classe desenvolve seu próprio habitus, ou seja, desenvolve um conjunto de disposições que são interiorizadas e objetivadas, disposições essas que acabam manifestando-se por meio de diferentes gostos de classes, diferenciando o que é "bonito" ou "feio", entre o que é erudito e popular, entre um vinho bom e outro ruim, entre uma alimentação de qualidade e outra de quantidade, ou ainda o que deve ser tratado como luxo e o que deve ser tratado como necessidade (BRANDÃO, 2010). Essa distinção (entre gostos) evidencia-se a partir das distintas classes sociais. Quando alguém adquire um objeto de custo elevado, como uma joia que custa mais de um milhão de reais, a classe operária não observa naquele objeto algo concreto de se adquirir, mas sim como se poderia aplicar aqueles milhões de reais com outro objeto. Em suma, o que é algo necessário para alguns pode parecer uma extravagância para outros.

É dentro deste contexto que, em uma análise sociológica, sob o ponto de vista bourdiesiano, o ajuste entre as preferências e as condições práticas de sua realização está associada ao habitus. A partir de um processo não espontâneo de adaptação, as condições objetivas de ação e os investimentos são ajustados entre si. Isso acarreta estratégias mais factíveis, mais adequadas e com menos riscos, as quais seriam adotadas por determinados grupos e, com isso, incorporadas ao habitus daqueles sujeitos.

Se voltarmos esse raciocínio para a educação, podemos dizer que grupos sociais, a partir de suas vivências em um determinado contexto social, possuem 
uma determinada expectativa em relação ao ambiente escolar e profissional, e adaptam, de maneira não deliberada, seus investimentos às chances de obterem êxito. Com isso, os sujeitos de um determinado grupo social possuem uma disposição maior ou menor de investir esforços no ambiente escolar, sejam esses esforços relacionados aos recursos econômicos, sejam eles relacionados ao tempo e também ao empenho dedicado a essas atividades (NOGUEIRA, 2010).

\section{SUJEITOS E DADOS DA ANÁLISE}

As informações utilizadas neste trabalho são referentes aos dados obtidos nos questionários socioeconômicos dos vestibulares da Universidade Federal de Santa Maria (UFSM) entre os anos de 2011 a 2014 e da Universidade Federal do Rio Grande do Sul entre os anos de 2013 a 2017. As escolhas por essas universidades estão associadas ao fato de serem duas universidades públicas situadas em diferentes regiões do estado do Rio Grande do Sul; uma delas situada no interior do estado e a outra localizada na capital. Dessa forma, duas diferentes regiões socioeconômicos poderiam ser melhor avaliadas e comparadas.

As informações foram obtidas a partir das respostas fornecidas pelos alunos durante a inscrição no processo seletivo. A diferença temporal entre as informações das duas instituições deve-se ao fato de a UFSM ter aderido ao Exame Nacional do Ensino Médio (Enem) para realizar o ingresso de seus alunos somente a partir do ano de 2015. Assim, essa universidade forneceu os resultados referentes apenas aos seus últimos concursos vestibulares.

Para realizarmos a análise dos resultados disponibilizados pelas universidades, organizamos os dados de acordo com os três cursos de Física de cada uma dessas instituições: o curso de Física - Licenciatura Plena Diurno, Física - Licenciatura Plena Noturno e Física Bacharelado. O nosso principal objetivo era analisar algum dos cursos de Licenciatura Plena, visto que existe uma carência na formação desse profissional. Como o curso de Física - Licenciatura Plena Noturno possui um público bastante heterogêneo, desde alunos egressos recentemente do Ensino Médio até trabalhadores estudantes que optam por esse horário a fim de conciliar suas atividades, nossa escolha para esse trabalho foi abordar apenas o curso de Física - Licenciatura Plena Diurno, pois a maior parte dos alunos que buscam esse curso são egressos recentes do Ensino Médio. Resultados referentes aos outros cursos (Física - Bacharelado e Física - Licenciatura Plena Noturno) serão apresentados em um artigo que está em fase de elaboração.

Para fazermos a análise quantitativa dos dados obtidos, realizamos uma média aritmética entre todos os participantes do concurso vestibular de cada uma das instituições avaliadas. Para cada um dos itens avaliados, uma determinada quantidade de candidatos ao curso de Física - Licenciatura Plena respondia ao questionamento do questionário socioeconômico. O número absoluto de respostas para cada um desses itens foi transformado em um valor percentual, conforme o número total de respostas. Os dados são apresentados nas tabelas da próxima seção. 


\section{ANÁLISE DOS QUESTIONÁRIOS SOCIOECONÔMICOS}

Para avaliarmos qualitativa e quantitativamente os dados supracitados, inicialmente foram escolhidas algumas variáveis dos questionários socioeconômicos. A escolha dessas variáveis relaciona-se às perguntas que envolvem diferentes formas de capital, como o capital cultural e econômico desses alunos. Nosso objetivo aqui é verificar as relações entre diferentes posições sociais dos candidatos e os aspectos relacionados às suas escolhas profissionais. Dividimos, assim, nossa análise de pesquisa em dois setores: o primeiro está associado à origem dos estudantes, se realizaram seus estudos de Ensino Médio em escola pública ou privada e quais foram os motivos que os levaram à escolha desse curso. O segundo está relacionado com a origem familiar dos candidatos: qual é a escolaridade dos pais? Qual é a opinião dos pais em relação à opção profissional de seu filho ou sua filha? Finalmente, analisamos a renda familiar de origem desses candidatos. Essa divisão em dois setores serve para organizarmos melhor nossa análise, pois as perguntas realizadas nos dois questionários socioeconômicos não são, necessariamente, as mesmas.

Tabela 1. UFSM - Como você fez seus estudos de Ensino Médio?

\begin{tabular}{l|c|c|c|c}
\hline \multirow{2}{*}{ Respostas } & \multicolumn{4}{|c}{ Anos } \\
\cline { 2 - 5 } & $\begin{array}{c}2011 \\
(\%)\end{array}$ & $\begin{array}{c}2012 \\
(\%)\end{array}$ & $\begin{array}{c}2013^{*} \\
(\%)\end{array}$ & $\begin{array}{c}2014 \\
(\%)\end{array}$ \\
\hline Todo em escola pública & 83,33 & 66,67 & - & 93,75 \\
\hline Maior parte em escola pública & 8,33 & - & - & 6,25 \\
\hline Todo em escola privada & - & - & - & - \\
\hline Maior parte em escola privada & 8,33 & - & - & - \\
\hline Supletivo & - & 33,33 & - & - \\
\hline
\end{tabular}

*No ano de 2013 a Universidade Federal de Santa Maria não disponibilizou em seu questionário socioeconômico para a referida pergunta.

Fonte: Elaborado pelo awutor.

Tabela 2. UFRGS - Onde você cursou a maior parte do Ensino Médio?

\begin{tabular}{l|c|c|c|c|c}
\hline \multirow{2}{*}{ Respostas } & \multicolumn{5}{|c}{ Anos } \\
\cline { 2 - 6 } & $\begin{array}{c}2013 \\
(\%)\end{array}$ & $\begin{array}{c}2014 \\
(\%)\end{array}$ & $\begin{array}{c}2015 \\
(\%)\end{array}$ & $\begin{array}{c}2016 \\
(\%)\end{array}$ & $\begin{array}{c}2017 \\
(\%)\end{array}$ \\
\hline Escola pública integralmente & 54 & 55 & 53 & 60 & 54 \\
\hline Escola pública maior parte & 8 & 8 & 7 & 3 & - \\
\hline Escola particular integralmente & 28 & 26 & 35 & 26 & 40 \\
\hline Escola particular maior parte & 10 & 11 & 5 & 11 & 6 \\
\hline
\end{tabular}

Fonte: Elaborado pelo autor.

Inicialmente verifica-se, a partir dos dados apresentados na Tabela 1, que a maior parte dos alunos que buscam o curso de Física - Licenciatura Plena na 
UFSM tem sua origem em escolas públicas de Ensino Médio. A mesma análise foi feita para o vestibular da UFRGS e os resultados encontrados na Tabela 2 indicam que, nos anos investigados, a maior parte dos alunos que busca o curso de Licenciatura em Física tem sua origem nas escolas públicas de Ensino Médio.

Na UFSM, em média 80\% dos candidatos que optam por esse curso são oriundos de escola pública, na UFRGS essa média está em torno de 55\% dos candidatos. Ou seja, a origem da maior parte desses indivíduos está associada a um histórico de frequência em escolas, muitas vezes, com problemas estruturais, com problemas financeiros e de baixa motivação de professores e funcionários devido aos baixos recursos destinados pela administração pública a esses setores (REZENDE, 2004).

Outro dado analisado nessa pesquisa é em relação à experiência no vestibular. As informações analisadas do vestibular da UFSM encontram-se na Tabela 3. Exceto em 2011, a maior parte dos concorrentes nunca havia realizado o concurso vestibular, ou então haviam realizado apenas uma vez. No ano de 2011, aproximadamente $17 \%$ dos candidatos nunca havia realizado o vestibular, enquanto quase $42 \%$ realizaram apenas uma vez esse concurso. Já nos anos de 2012 e 2013, a porcentagem de alunos que estavam buscando o ingresso em um curso de Licenciatura em Física, pela primeira vez, chega em torno de $65 \%$ do total dos candidatos. Ou seja, a primeira experiência em um concurso vestibular, em geral, ocorre quando disputam uma vaga para o curso de Licenciatura em Física nessa instituição.

A UFRGS faz o mesmo questionamento aos alunos através da pergunta: "Quantas vezes você já prestou o vestibular na UFRGS? ”. Os resultados estão mais bem descritos na Tabela 4. Nessa instituição, a pergunta é direcionada à universidade, porém, a fim de uma análise comparativa entre as duas instituições, o dado é relevante. Com os resultados observados nesse trabalho, é possível identificar que a maior parte dos alunos está realizando pela primeira vez o vestibular nessa instituição. A primeira opção desses candidatos ocorre para o curso de Licenciatura em Física. Ou seja, mesmo com os inúmeros cursos de graduação que as duas instituições oferecem para sua escolha, esses resultados nos remetem à ideia de uma preferência por tal curso por parte dos estudantes.

Tabela 3. UFSM - Quantas vezes você fez vestibular?

\begin{tabular}{l|c|c|c|c}
\hline \multirow{2}{*}{ Respostas } & \multicolumn{4}{|c}{ Anos } \\
\cline { 2 - 5 } & $\begin{array}{c}2011 \\
(\%)\end{array}$ & $\begin{array}{c}2012 \\
(\%)\end{array}$ & $\begin{array}{c}2013 \\
(\%)\end{array}$ & $\begin{array}{c}2014 \\
(\%)\end{array}$ \\
\hline Nenhuma & 16,67 & 66,67 & 64,29 & 31,25 \\
\hline 01 vez & 41,67 & 33,33 & 14,29 & 37,5 \\
\hline 02 vezes & 33,33 & - & 14,29 & 12,5 \\
\hline 03 vezes ou mais & 8,33 & - & 7,14 & 18,75 \\
\hline
\end{tabular}

Fonte: Elaborado pelo autor. 
Tabela 4. UFRGS - Quantas vezes você já prestou o vestibular na UFRGS?

\begin{tabular}{l|c|c|c|c|c}
\hline \multirow{2}{*}{ Respostas } & \multicolumn{5}{c}{ Anos } \\
\cline { 2 - 6 } & $\begin{array}{c}2013 \\
(\%)\end{array}$ & $\begin{array}{c}2014 \\
(\%)\end{array}$ & $\begin{array}{c}2015 \\
(\%)\end{array}$ & $\begin{array}{c}2016 \\
(\%)\end{array}$ & $\begin{array}{c}2017^{*} \\
(\%)\end{array}$ \\
\hline Nenhuma vez & 43 & 56 & 58 & 40 & - \\
\hline Uma vez & 34 & 31 & 21 & 32 & - \\
\hline Duas vezes & 10 & 5 & 17 & 19 & - \\
\hline Três vezes & 5 & - & 2 & 3 & - \\
\hline Quatro vezes & 5 & 4 & 2 & 4 & - \\
\hline Mais de quatro vezes & 3 & 4 & & 2 & - \\
\hline
\end{tabular}

*No ano de 2017, a Universidade Federal do Rio Grande do Sul não disponibilizou em seu questionário socioeconômico a referida pergunta.

Fonte: Elaborado pelo autor.

Ainda em busca de uma melhor compreensão do perfil dos estudantes que procuram ingressar na carreira docente na área de Física, analisamos qual foi o principal motivo, na opinião deles, que os levou a optarem por realizar o vestibular nessa área. Esse questionamento não foi realizado no vestibular da UFRGS, por isso não será analisado aqui nesse trabalho. Na UFSM, quando os alunos são questionados pela pergunta "Qual o principal motivo que o levou a optar pelo curso em que está se inscrevendo?", em todos os anos avaliados a maior parte dos alunos relata que o principal motivo associado à escolha é o atendimento às aptidões desses, tendo apenas o ano de 2012 apresentado um maior equilíbrio entre a opção de "prestígio social" e "outro motivo". Nos anos de 2012, 2013 e 2014, a porcentagem de candidatos que assinalam a opção "Atendimento de minhas aptidões pessoais" é de, aproximadamente, 33\%, 72\% e 63\%, respectivamente. Os resultados referentes a esse questionamento encontram-se na Tabela 5.

Apesar do curso de Física Licenciatura Plena - Diurno da Universidade Federal de Santa Maria apresentar baixa concorrência comparado com outros cursos dessa mesma instituição (entre os anos de 2011 a 2014 a relação candidato/ vaga variou entre 0,2 e 1,5), apenas no ano de 2013, 7,14\% dos concorrentes assinalaram a opção que relacionava sua escolha à pequena concorrência do curso.

É interessante notar que os cursos de licenciatura plena, em geral, possuem um baixo prestígio social por parte da população brasileira (XAVIER, 2014). Entre os mais diversos motivos, é possível destacar os baixos investimentos públicos, os evidentes processos de desvalorização do profissional da educação, além das baixas possibilidades de desenvolvimento profissional, quando comparadas com outras carreiras (LIMA, 2014). A análise dos resultados do nosso trabalho apresenta um aspecto relevante entre essa perspectiva e os dados apreciados nos questionários socioeconômicos. Seria razoável esperar que, por não ter um prestígio social tão elevado e por ter uma pequena concorrência, o fator da baixa concorrência poderia ser um dos principais motivos na hora de escolher do curso de Licenciatura em Física, porém esse motivo não apresenta grande destaque em nenhum dos anos analisados. 
Tabela 5. UFSM - Qual o principal motivo que o levou a optar pelo curso em que está se inscrevendo?

\begin{tabular}{l|c|c|c|c}
\hline \multirow{2}{*}{ Respostas } & \multicolumn{4}{|c}{ Anos } \\
\cline { 2 - 5 } & $\begin{array}{c}2011 \\
(\%)\end{array}$ & $\begin{array}{c}2012 \\
(\%)\end{array}$ & $\begin{array}{c}2013 \\
(\%)\end{array}$ & $\begin{array}{c}2014 \\
(\%)\end{array}$ \\
\hline Atendimento de minhas aptidões e interesses & 33,33 & 33,33 & 71,43 & 62,5 \\
\hline $\begin{array}{l}\text { Compatibilidade de horário com minha atual } \\
\text { profissão }\end{array}$ & - & - & - & 6,25 \\
\hline Prestígio social da profissão & 16,67 & 33,33 & - & 6,25 \\
\hline Facilidade de mercado de trabalho & 16,67 & - & - & 6,25 \\
\hline Bom nível de exigência do curso & 25 & - & - & 12,5 \\
\hline $\begin{array}{l}\text { Aperfeiçoamento de meu exercício profissional } \\
\text { atual }\end{array}$ & 8,33 & - & 7,14 & - \\
\hline Pequena concorrência às vagas & - & - & 7,14 & - \\
\hline Outro motivo & - & 33,33 & 14,29 & 6,25 \\
\hline
\end{tabular}

Fonte: Elaborado pelo autor.

Para tentar compreender melhor o processo de escolha pelo curso de Licenciatura em Física, voltamos nossa atenção para a Sociologia da Educação. Os gostos individualmente manifestados são construções sociais relacionadas às histórias de vida de cada pessoa. De acordo com Pierre Bourdieu (2007), os indivíduos adaptam seus gostos por aquilo que é possível de ser alcançado, algo que possa efetivamente ser realizado. Para o autor, esse movimento pode ser identificado por "gosto pelo possível". Uma pessoa que reconheça como um potencial objetivo profissional o curso de Licenciatura em Física irá direcionar sua atenção para essa profissão, incorporando esse objetivo como uma meta a ser alcançada. Suas ações são, assim, adequadas não só pelo gosto, mas também por razões práticas.

A relação do capital econômico e cultural no processo de escolha profissional também foi investigada nessa pesquisa. Dos dados apresentados no questionário socioeconômico, analisamos os seguintes questionamentos: "Qual a escolaridade do seu pai?", "Qual a escolaridade da sua mãe?", "Qual a renda total, em salários mínimos, da família?” e "Qual a posição dos seus pais ou responsáveis diante de sua escolha profissional?". Com efeito, nosso objetivo foi compreender se o ambiente familiar é relevante nessa escolha. Nas duas instituições estudadas, é possível analisar os resultados referentes às escolaridades dos pais e das mães desses concorrentes. Os resultados referentes à UFSM (Tabela 6) mostram que a maior parte dos pais dos candidatos às vagas desse curso possui baixo nível de escolarização. Com exceção de 2013, em todos os anos analisados a maior parte dos pais possui o Ensino Fundamental incompleto ou então o Ensino Médio completo. Apenas nos anos de 2011 e 2014, 8,33\% e 12,5\%, respectivamente, dos candidatos pertencem a famílias em que os pais possuem cursos de pós-graduação. 
Tabela 6. UFSM - Qual a escolaridade do seu pai?

\begin{tabular}{l|c|c|c|c}
\hline \multirow{2}{*}{ Respostas } & \multicolumn{4}{|c}{ Anos } \\
\cline { 2 - 5 } & $\begin{array}{c}2011 \\
(\%)\end{array}$ & $\begin{array}{c}2012 \\
(\%)\end{array}$ & $\begin{array}{c}2013 \\
(\%)\end{array}$ & $\begin{array}{c}2014 \\
(\%)\end{array}$ \\
\hline Primário ou $1^{\circ}$ grau incompleto & 41,67 & 66,67 & 21,43 & 31,25 \\
\hline $1^{\circ}$ grau incompleto & 16,67 & - & 28,57 & 12,5 \\
\hline Ensino Médio & 33,33 & 33,33 & 35,71 & 31,25 \\
\hline Curso Superior & - & - & - & 12,5 \\
\hline Curso de Pós Graduação & 8,33 & - & - & 12,5 \\
\hline Outra situação & - & - & 14,29 & - \\
\hline
\end{tabular}

Fonte: Elaborado pelo autor.

Tabela 7. UFRGS - Qual o nível de escolaridade do seu pai?

\begin{tabular}{l|c|c|c|c|c}
\hline \multirow{2}{*}{ Respostas } & \multicolumn{5}{|c}{ Anos } \\
\cline { 2 - 6 } & $\begin{array}{c}2013 \\
(\%)\end{array}$ & $\begin{array}{c}2014 \\
(\%)\end{array}$ & $\begin{array}{c}2015 \\
(\%)\end{array}$ & $\begin{array}{c}2016 \\
(\%)\end{array}$ & $\begin{array}{c}2017 \\
(\%)\end{array}$ \\
\hline Não alfabetizado & - & - & 3 & - & - \\
\hline Ensino Fundamental Incompleto & 20 & 17 & 13 & 18 & 18 \\
\hline Ensino Fundamental Completo & 7 & 8 & 6 & 7 & 2 \\
\hline Ensino Médio Incompleto & 6 & 13 & 6 & 12 & 5 \\
\hline Ensino Médio Completo & 38 & 33 & 30 & 22 & 27 \\
\hline Ensino Superior Incompleto & 6 & 15 & 13 & 6 & 18 \\
\hline Ensino Superior Completo & 18 & 10 & 21 & 13 & 18 \\
\hline Pós Graduação & 5 & 4 & 8 & 22 & 12 \\
\hline
\end{tabular}

Fonte: Elaborado pelo autor.

Na UFRGS (Tabela 7) a situação é semelhante à UFSM. Em todos os anos analisados, a maior parte dos pais desses concorrentes possui o Ensino Médio completo. Porém, é possível observar um incremento no número de pais com Ensino Superior completo e também alguns pais com cursos de pós-graduação.

Em relação à escolaridade das mães, em ambas as universidades é possível observar um perfil semelhante à escolaridade dos pais. A maior parte dos entrevistados disse que suas mães possuem Ensino Médio completo, como mostram os resultados referentes à UFSM na Tabela 8. O que muda, nesse caso, é que é possível observar números mais frequentes de mães de candidatos que possuem cursos de graduação e pós-graduação. Na UFRGS, dependendo do ano analisado, em torno de $20 \%$ dos candidatos são oriundos de famílias em que as mães possuem Ensino Superior e, em alguns anos, é possível observar que até 16\% das mães possuem cursos de pósgraduação. Esses resultados podem ser observados na Tabela 9. 
Tabela 8. UFSM - Qual a escolaridade de sua mãe?

\begin{tabular}{l|c|c|c|c}
\hline \multirow{2}{*}{ Respostas } & \multicolumn{4}{|c}{ Anos } \\
\cline { 2 - 5 } & $\begin{array}{c}2011 \\
(\%)\end{array}$ & $\begin{array}{c}2012 \\
(\%)\end{array}$ & $\begin{array}{c}2013 \\
(\%)\end{array}$ & $\begin{array}{c}2014 \\
(\%)\end{array}$ \\
\hline Primário ou $1^{\circ}$ grau incompleto & 16,67 & 66,67 & 7,14 & 12,5 \\
\hline Primário completo & 8,33 & - & 7,14 & 6,25 \\
\hline $1^{\circ}$ grau completo & 25 & 33,33 & 14,29 & 25 \\
\hline Ensino Médio & 41,67 & - & 50 & 6,25 \\
\hline Curso Superior & 8,33 & - & 21,43 & 25 \\
\hline Curso de Pós-Graduação & - & - & - & 25 \\
\hline
\end{tabular}

Fonte: Elaborado pelo autor.

Tabela 9. UFRGS - Qual o nível de escolaridade da sua mãe?

\begin{tabular}{l|c|c|c|c|c}
\hline \multirow{2}{*}{ Respostas } & \multicolumn{5}{|c}{ Anos } \\
\cline { 2 - 6 } & $\begin{array}{c}2013 \\
(\%)\end{array}$ & $\begin{array}{c}2014 \\
(\%)\end{array}$ & $\begin{array}{c}2015 \\
(\%)\end{array}$ & $\begin{array}{c}2016 \\
(\%)\end{array}$ & $\begin{array}{c}2017 \\
(\%)\end{array}$ \\
\hline Não alfabetizado & - & - & 3 & - & - \\
\hline Ensino Fundamental Incompleto & 25 & 24 & 4 & 14 & 10 \\
\hline Ensino Fundamental Completo & 3 & 2 & 11 & 6 & 4 \\
\hline Ensino Médio Incompleto & 9 & 6 & 6 & 14 & 8 \\
\hline Ensino Médio Completo & 21 & 28 & 28 & 22 & 37 \\
\hline Ensino Superior Incompleto & 9 & 8 & 9 & 8 & 6 \\
\hline Ensino Superior Completo & 25 & 21 & 21 & 23 & 19 \\
\hline Pós Graduação & 8 & 11 & 18 & 13 & 16 \\
\hline
\end{tabular}

Fonte: Elaborado pelo autor.

De acordo com Bourdieu (1992), é possível para um indivíduo acumular capital econômico, capital cultural e capital social. $\mathrm{O}$ autor defende que existe uma correlação entre a origem familiar e o sucesso escolar. Bourdieu utiliza o capital cultural para justificar como uma sociedade, dividida em classes sociais, reproduz seus processos de desigualdades, porém nossos resultados indicam apenas uma tendência que alunos que provêm de famílias com menor número de anos empenhados na educação tendem a escolher o curso de Física Licenciatura Plena. Para verificar um sistema de reprodução, seria necessário analisar outros cursos dessas instituições, trabalho esse que está em processo de elaboração.

Para compreender as características sociais dos indivíduos que optam pelo curso de Licenciatura em Física da UFSM e da UFRGS, escolhemos analisar também o capital econômico dessas famílias. Os resultados da UFSM, mostrados 
na Tabela 10, indicam que apenas uma pequena parcela dos entrevistados diz pertencer a uma família com renda de até um salário mínimo. Esse número foi obtido no ano de 2014 , em que $12,5 \%$ das pessoas responderam pertencer a esse grupo. Com exceção do ano de 2013, para o qual essa pergunta não foi realizada no questionário socioeconômico, nos demais anos a maior parte dos alunos que concorrem a esse curso pertence a grupos familiares com renda total entre 1 e 2 salários mínimos e entre 2 e 3 salários mínimos, indicando que a maioria dos indivíduos que buscam a formação de professor de Física nessa instituição vem de famílias com baixo poder aquisitivo.

Tabela 10. UFSM - Qual a renda total mensal, em salários mínimos, da família?

\begin{tabular}{l|c|c|c|c}
\hline Respostas & \multicolumn{4}{c}{ Anos } \\
\hline (salários mínimos) & $\begin{array}{c}2011 \\
(\%)\end{array}$ & $\begin{array}{c}2012 \\
(\%)\end{array}$ & $\begin{array}{c}2013 \\
(\%)\end{array}$ & $\begin{array}{c}2014 \\
(\%)\end{array}$ \\
\hline Até 01 & - & - & - & 12,5 \\
\hline De 01 até menos de 02 & 25 & 33,33 & - & 31,25 \\
\hline De 02 até menos de 03 & 33,33 & 33,33 & - & 18,75 \\
\hline De 03 até menos de 04 & 8,3 & - & - & 6,25 \\
\hline De 04 até menos de 05 & - & - & - & 6,25 \\
\hline De 05 até menos de 07 & 16,67 & 33,33 & - & 18.75 \\
\hline De 07 até menos de 09 & 16,67 & - & - & 6,25 \\
\hline
\end{tabular}

Fonte: Elaborado pelo autor.

Tabela 11. UFRGS - Qual é, em salário mínimo nacional, a renda total mensal da sua família?

\begin{tabular}{l|c|c|c|c|c}
\hline Respostas & \multicolumn{5}{|c}{ Anos } \\
\hline (salários mínimos) & $\begin{array}{c}2013 \\
(\%)\end{array}$ & $\begin{array}{c}2014 \\
(\%)\end{array}$ & $\begin{array}{c}2015 \\
(\%)\end{array}$ & $\begin{array}{c}2016 \\
(\%)\end{array}$ & $\begin{array}{c}2017 \\
(\%)\end{array}$ \\
\hline Até 1 & 8 & 6 & & 5 & 6 \\
\hline De 1 até 2 & 12 & 15 & 23 & 22 & 18 \\
\hline De 2 até 3 & 26 & 12 & 16 & 9 & 13 \\
\hline De 3 até 4 & 13 & 20 & 15 & 11 & 15 \\
\hline De 4 até 5 & 13 & 12 & 11 & 13 & 13 \\
\hline De 5 até 10 & 13 & 23 & 20 & 25 & 13 \\
\hline De 10 até 20 & 12 & 10 & 10 & 11 & 22 \\
\hline De 20 até 30 & 3 & 2 & 4 & 3 & \\
\hline Mais de 30 & & & 1 & 1 & \\
\hline
\end{tabular}

Fonte: Elaborado pelo autor. 
Fazendo uma análise desse perfil no concurso vestibular da UFRGS, é observado, na Tabela 11, um comportamento mais heterogêneo, em que pessoas oriundas de vários grupos sociais concorreram a vagas para o curso de formação profissional de professores de Física.

Tabela 12. Qual a posição dos seus pais ou responsáveis diante de usa escolha profissional?

\begin{tabular}{l|c|c|c|c}
\hline \multirow{2}{*}{ Respostas } & \multicolumn{4}{|c}{ Anos } \\
\cline { 2 - 5 } & $\begin{array}{c}2011 \\
(\%)\end{array}$ & $\begin{array}{c}2012 \\
(\%)\end{array}$ & $\begin{array}{c}2013 \\
(\%)\end{array}$ & $\begin{array}{c}2014 \\
(\%)\end{array}$ \\
\hline Aprovam & 83,33 & 100 & 92,86 & 93,75 \\
\hline Indiferentes & 8,33 & - & - & 6,25 \\
\hline Não aprovam & - & - & - & - \\
\hline Não conhecem a minha escolha & 8,33 & & & \\
\hline Outra & - & - & 7,14 & - \\
\hline
\end{tabular}

Fonte: Elaborado pelo autor.

Conforme discutido, de acordo com a escolaridade dos pais e das mães das pessoas que responderam a esse questionário, observa-se que possuem, em sua maioria, o ensino básico completo e/ou incompleto. Para compreender se existe uma correlação entre a escolaridade dos pais e sua influência na escolha profissional, analisamos, no questionário socioeconômico da UFSM, o posicionamento dos pais diante da sua escolha profissional, resultados esses mostrados na Tabela 12. Em todos os anos analisados, a maior parte dos pais aprova a escolha dos filhos. Em todos os anos analisados, mais de $90 \%$ dos entrevistados dizem que seus pais ou responsáveis aprovam sua escolha pelo curso de Licenciatura em Física.

\section{CONSIDERACְÕES FINAIS}

Os resultados obtidos com esse trabalho e suas análises sugerem indícios relevantes para se apreciar alguns aspectos sociais no momento da escolha profissional em cursos de Física - Licenciatura Plena de duas diferentes instituições de Ensino Superior.

Focamos nossa atenção na origem escolar dos alunos concorrentes a uma vaga no curso de Física Licenciatura da UFSM e da UFRGS. Um aspecto relevante em relação aos concorrentes para o curso de Licenciatura em Física dessas instituições é que a maior parte dessas pessoas possui sua formação em escolas públicas. Outro elemento observado é que a maior parte está realizando o concurso vestibular pela primeira vez e que nunca frequentaram um curso de nível superior.

Outro campo analisado nesse trabalho é a origem familiar desses concorrentes. Nos anos aqui investigados, observa-se que os alunos que buscam um curso de Licenciatura em Física nessas universidades são, em geral, oriundos de classes sociais menos privilegiadas, em que a maior parte de suas famílias possuem 
renda total entre 2 e 3 salários mínimos. Um outro dado relevante é a escolaridade dos pais. A maior parte dos alunos que está buscando o ingresso nesse curso tem sua origem em famílias nas quais pais e mães possuem baixo nível de escolaridade, ou seja, apenas alguns desses familiares conhecem a realidade de um curso de nível de graduação ou pós-graduação. Esses pais aprovam, quase em sua totalidade, a opção do seu filho ou filha na escolha do curso de Licenciatura em Física ou então desconhecem o curso o qual o filho ou filha está escolhendo.

De acordo com Pierre Bourdieu, o gosto ou aptidões individuais não podem ser deslocados de um contexto macrossociológico (BOURDIEU, 2007). Para o autor, os indivíduos adaptam seus gostos para o que é possível de ser realizado. $\mathrm{O}$ autor afirma que o indivíduo possui um gosto pelo necessário; gosto pelo que é possível de ser objetivado. Pelos nossos resultados, os alunos manifestam como principal motivo de escolher esse curso o atendimento às suas aptidões e interesses. Uma pequena parcela associa a escolha desse curso a uma baixa concorrência, sendo que em um curso de Licenciatura em Física a densidade de candidatos por vaga é quase igual ao número de candidatos inscritos, o que indica que possa haver aqui um ajuste de seus gostos por aquilo que é possível de ser alcançado.

Pela nossa interpretação, a preferência manifestada pelos alunos pode estar associada à construção social em relação ao meio que esse candidato está inserido, assim como às oportunidades que esse indivíduo teve. Assim, o fato de a ampla maioria responder que está atendendo às suas aptidões não está, necessariamente, associado ao fato desses alunos realmente buscarem a carreira docente. Por outro lado, esse fato pode também estar relacionado a uma conjuntura estrutural que faz com que a escolha seja direcionada para uma profissão mais próxima à estrutura social a qual esse indivíduo pertence.

Apesar de, no Brasil, as políticas públicas dos últimos tempos estarem dispostas a modificar a realidade da educação no país, ainda é preciso um grande empenho dos agentes públicos para modificar tal realidade, a começar pela valorização dos profissionais da educação. Baixos salários, pequenos investimentos em infraestrutura e formação continuada desses profissionais servem para desestimular o professor, bem como atrair menos pessoas para essas áreas.

\section{REFERÊNCIAS}

BOURDIEU, P.; PASSERON, J-C. A Reprodução, elementos para uma teoria do sistema de ensino. Rio de Janeiro: Francisco Alves, 1992.

BOURDIEU, P. A Distinção: Crítica Social do Julgamento. Porto Alegre: Zouk, 2007.

BOURDIEU, P. Capital Cultural, Escuela y Espacio Social. México: Siglo Veinteuno, 1997.

BOURDIEU. P. Meditações Pascalianas. Trad. Sergio Miceli. Rio de Janeiro: Bertrand Brasil, 2001.

BRANDÃO, Z. Operando com conceitos: com e para além de Bourdieu. Educação e Pesquisa. v.36, n.1, p. 227-241, jan/abr. 2010.

BRASIL. Portaria n ${ }^{\circ}$ 794, de 23 de agosto de 2013. Dispõe sobre o Censo da Educação Superior. Disponível em <http://www.lex.com.br/legis_24761865_PORTARIA_N_794_DE_23_DE_ AGOSTO_DE_2013.aspx >: Acesso em: 20 jul. 2018. 
CERDEIRA, D. G. S. Mapeando o Perfil Docente de Escolas de Prestígios: Contribuição Para a Compreensão do Sucesso Escolar. 2008. 131f. Dissertação de Mestrado (Programa de PósGraduação em Educação do Departamento de Educação da PUC-Rio.). Pontifícia Universidade Católica do Rio de Janeiro, Rio de Janeiro, 2008.

DINIZ-PEREIRA, J. E. A situação atual dos cursos de licenciatura no Brasil frente à hegemonia da educação mercantil e empresarial. Revista Eletrônica de Educação, v. 9, n. 3, p. 273-280, 2015.

IBAÑEZ RUIZ, A. I.; RAMOS, M. N.; HINGEL, M. Escassez de professores no Ensino Médio: soluções emergenciais e estruturais. Brasília: Câmara de Educação Básica, 2007. Disponível em: <http://portal.mec.gov.br/cne/arquivos/pdf/escassez1.pdf>. Acesso em 28 jun. 2018.

LIMA, E.; MACHADO, L. A evasão discente nos cursos de licenciatura da Universidade Federal de Minas Gerais. Educação Unisinos. v. 18, n. 2, p. 121-129, 2014.

LÜDKE, M.; BOING, L. A. Caminhos da profissão e da profissionalidade docentes. Educação \& Sociedade. v. 25, n. 89, p.1159-1180, 2004.

LUNKES, M. J.; ROCHA FILHO, J. B. A baixa procura pela Licenciatura em Física, com base em depoimentos de estudantes do Ensino Médio público do oeste catarinense. Ciência \& Educação, v. 17 , n. 1, p. 21-34, 2011.

NOGUEIRA, C. M. M; PEREIRA, F. G. O gosto e as condições de sua realização: a escolha por pedagogia entre os estudantes com perfil social e escolar mais elevado. v. 26, n. 3, p.15-38, 2010.

OLIVEIRA, D. R.; PIFFER, C. C. G.; GUIMARÃES, C. M. Os fatores de influência no processo de escolha pelo curso de pedagogia na Unesp de Presidente Prudente e UFMS de Corumbá. In: XI Congresso Nacional de Educação. p. 11232-11244, Curitiba. 2013.

ORTIZ, R. A procura de uma Sociologia da prática. In: BOURDIEU, P. Pierre Bourdieu: Sociologia. São Paulo: Ática, 1983.

REZENDE, F; LOPES, A. M. A; EGG, J. M. Identificação de Problemas do Currículo, do Ensino e da Aprendizagem de Física e de Matemática a partir do discurso de professor. Ciência \& Educação. v. 10, n. 2, p. 185-196, 2004.

RODRIGUES, M. A.; TEIXEIRA, F. M. Reflexões sobre a baixa procura pelo curso de Física nas Universidades Federais de Pernambuco. In: VII Encontro Nacional de Pesquisa em Educação em Ciências. v.1, p. 1-11, Florianópolis. Anais VII ENPEC, 2009.

SANTOS, L. M. O que leva alguém a querer ser professor? Em blogs e no Facebook, narrativas de professores em formação inicial contam sobre as escolhas pela profissão. Renote: Revista Novas Tecnologias na Educação, v. 11, n. 3, Porto Alegre, 2013.

SÁ, C. S. S; SANTOS, W. L. P. Licenciatura em Química: carência de professores, condições de trabalho e motivação pela carreira docente. In: VIII Encontro Nacional de Pesquisa em Educação em Ciências. Campinas. Atas do VIII ENPEC, 2011.

XAVIER, L. N. A construção social e histórica da profissão docente. Revista Brasileira de Educação v. 19 n. 59, out./dez., 2014.

Submetido em 28/06/2018

Aprovado em 06/12/2018

\section{Contato:}

Instituto Federal de Educação, Ciência e Tecnologia do Rio Grande do Sul/Campus Bento Gonçalves

Avenida Osvaldo Aranha, 540, Sala A201 - Juventude da Enologia

CEP 95.700-206 - Bento Gonçalves, RS - Brasil 